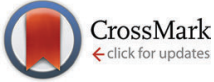

Cite this: J. Mater. Chem. C, 2016, 4, 5320

Received 10th March 2016, Accepted 4th May 2016

DOI: $10.1039 / c 6 t c 01034 b$

www.rsc.org/MaterialsC

\section{The structure, chemistry and magnetic properties of $\mathrm{FePbBiO}_{4}$}

\author{
Benjamin P. de Laune, ${ }^{a}$ Frank J. Berry, ${ }^{a}$ Jose F. Marco, ${ }^{b}$ Sarah L. Horswell ${ }^{a}$ and \\ Colin Greaves*a
}

\section{Introduction}

The mineral schafarzikite, $\mathrm{FeSb}_{2} \mathrm{O}_{4}$, has been reported to be tetragonal $\left(P 4_{2} / m b c, a=8.62 \AA \text { and } c=5.91 \AA\right)^{1}$ with one-dimensional features: chains of edge-linked $\mathrm{FeO}_{6}$ octahedra are aligned along [001] and enclose parallel channels. This is illustrated in Fig. 1 for the detailed structure of the new compound reported here, $\mathrm{FePbBiO}_{4}$ (or $\mathrm{Fe}(\mathrm{PbBi})_{2} \mathrm{O}_{4}$ ), where one $\mathrm{Pb}^{2+}$ and one $\mathrm{Bi}^{3+}$ ion have replaced two $\mathrm{Sb}^{3+}$ ions. $\mathrm{In} \mathrm{FeSb}_{2} \mathrm{O}_{4}$, therefore, $\mathrm{Sb}^{3+}$ ions link the $\mathrm{FeO}_{6}$ octahedra via their apical (O1) and equatorial (O2) ligands and form $\mathrm{SbO}_{3}$ trigonal pyramids. The $\mathrm{Sb}^{3+}$ lone pairs (e) are directed into the channels and provide pseudo-tetrahedral $\mathrm{SbO}_{3} \mathrm{e}$ coordination. Strong intrachain magnetic exchange (primarily direct orbital overlap between adjacent $\mathrm{Fe}^{2+}$ ions) results in A-type magnetic order (Fig. 2a) below the Néel temperature, $T_{\mathrm{N}}=46 \mathrm{~K}^{2,3}$

Related $\mathrm{MSb}_{2} \mathrm{O}_{4}$ materials $(\mathrm{M}=$ magnetic transition metal) are known for $\mathrm{M}=\mathrm{Mn}, \mathrm{Co}, \mathrm{Ni}, \mathrm{Cu}$ and $\mathrm{Zn}^{4-8}$ All order magnetically at low temperatures except for $\mathrm{CuSb}_{2} \mathrm{O}_{4}$, which appears to show no long range order above $2 \mathrm{~K},{ }^{9}$ and $\mathrm{ZnSb}_{2} \mathrm{O}_{4}$, which is diamagnetic. Whereas the phases with $\mathrm{M}=\mathrm{Mn}$, Fe display predominantly A-type magnetic order (Fig. 2a), the $\mathrm{M}=\mathrm{Co}$, Ni phases are C-type antiferromagnets (Fig. 2b). ${ }^{1,10,11}$ It has been suggested that the nature of the direct exchange within the chains - size of cation, $\mathrm{M}-\mathrm{M}$ separation distance and occupancy of the $t_{2 g}$ orbitals - is responsible for the change in magnetic order. ${ }^{11,12}$ The $90^{\circ} \mathrm{M}-\mathrm{O}-\mathrm{M}$ intrachain exchange is expected to be ferromagnetic but weak for all ions in the series $\mathrm{Mn} \cdots \mathrm{Ni}$. However, $\mathrm{Mn}^{2+}$ and $\mathrm{Fe}^{2+}$ experience strong direct

\footnotetext{
${ }^{a}$ School of Chemistry, University of Birmingham, Birmingham B15 2TT, UK. E-mail: c.greaves@bham.ac.uk

${ }^{b}$ Instituto de Quimica-Fisica "Rocasolano", CSIC, Serrano 119, 28006 Madrid, Spain
}

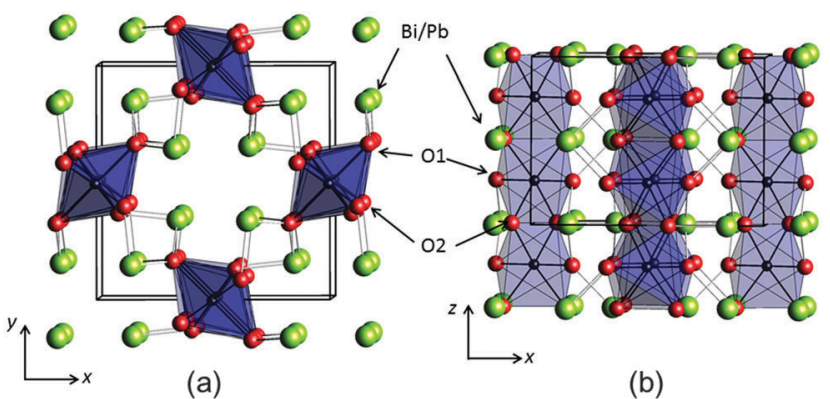

Fig. 1 The structure of $\mathrm{FePbBiO}_{4}$ structure viewed (a) along [001] and (b) approximately along [010]. Fe - black within blue octahedra, $\mathrm{Pb} / \mathrm{Bi}$ - large green spheres, $\mathrm{O}$ - red spheres (O1 apical and $\mathrm{O} 2$ equatorial).

antiferromagnetic exchange because the $t_{2 g}$ orbitals are relatively diffuse; this allows overlap of orbitals on adjacent cation sites to give an antiferromagnetic groundstate. Across the series from $\mathrm{Mn}$ to $\mathrm{Ni}$, the d-orbitals contract and the $\mathrm{t}_{2 \mathrm{~g}}$ orbitals fill up both of which weaken the direct exchange such that intrachain ferromagnetic order occurs to give, overall, C-type order. In confirmation of these basic principles, the change in magnetic order for the series $\mathrm{Fe}_{x} \mathrm{Co}_{1-x} \mathrm{Sb}_{2} \mathrm{O}_{4}$ and $\mathrm{Mn}_{x} \mathrm{Co}_{1-x} \mathrm{Sb}_{2} \mathrm{O}_{4}, 0 \leq x \leq 1$ has recently been reported and shows a gradual change from A-type to C-type as $x$ decreases. ${ }^{12}$

Attempts to functionalise some materials by creating mixed $\mathrm{M}^{2+} / \mathrm{M}^{3+}$ oxidation states have been reported via substitution of $\mathrm{Pb}^{2+}$ for $\mathrm{Sb}^{3+}$ for $\mathrm{M}=\mathrm{Mn}, \mathrm{Fe}$ and Co. ${ }^{11,13,14}$ However, only for $\mathrm{M}=\mathrm{Fe}$ is oxidation of the transition metal favoured over oxidation of $\mathrm{Sb}^{3+}$ to $\mathrm{Sb}^{5+} \cdot{ }^{13}$ Even for this system, $\mathrm{FeSb}_{2-x} \mathrm{~Pb}_{x} \mathrm{O}_{4}$, pure crystalline products were obtained only for $x \leq 0.7$ and no phase containing $100 \% \mathrm{Fe}^{3+}$ (requiring equal amounts of +2 and +3 charged lone pair cations) has been reported. 
(a)

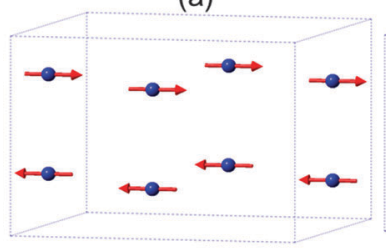

(c)

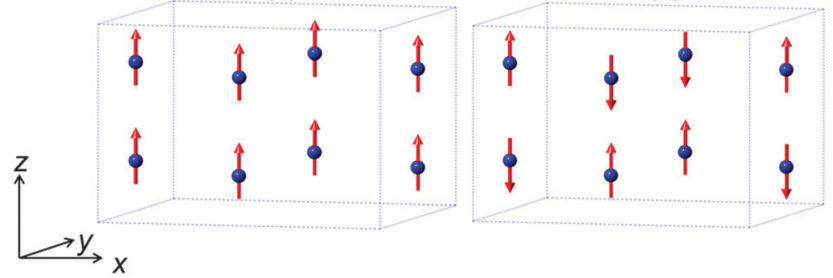

Fig. 2 The four possible collinear spin alignments generating the basic observed magnetic structures for $\mathrm{MSb}_{2} \mathrm{O}_{4}$ phases: (a) A-type, (b) C-type, (c) F-type and (d) G-type.

The magnetic properties of such a material are of interest because the direct exchange would be expected to be weaker than in the $\mathrm{Fe}^{2+}$ compound, $\mathrm{FeSb}_{2} \mathrm{O}_{4}$, such that the resultant magnetic order is not simple to predict. It is also strange that no schafarzikitetype phase containing $\mathrm{Bi}^{3+}$ ions has been reported since the ionic radius of $\mathrm{Bi}^{3+}(1.03 \AA)$ is intermediate between those of $\mathrm{Pb}^{2+}$ $(1.19 \AA)$ and $\mathrm{Sb}^{3+}(0.76 \AA)$; these data are for 6 -coordinate ions since data are not given for 3 -coordination. ${ }^{15}$ In the present study, we examined the use of the similarly sized cations $\mathrm{Pb}^{2+}$ and $\mathrm{Bi}^{3+}$ and we report the successful synthesis, structure, magnetic properties and chemistry of the resultant product $\mathrm{FePbBiO}_{4}$ : the first schafarzikite compound to contain only +3 cations within the chains of octahedra and the first to contain $\mathrm{Bi}^{3+}$ cations.

\section{Experimental}

A polycrystalline sample of $\mathrm{FePbBiO}_{4}$ was synthesised by heating an intimate mixture of pre-dried $\mathrm{Fe}_{2} \mathrm{O}_{3}$ (99\%, Aldrich), $\mathrm{PbO}$ (99.9\%, Aldrich) and $\mathrm{Bi}_{2} \mathrm{O}_{3}(99.9 \%$, Aldrich) in the appropriate stoichiometric amounts. The mixture was heated in air for two periods of $7 \mathrm{~h}$ at $650{ }^{\circ} \mathrm{C}$ in an alumina boat.

X-Ray powder diffraction (XRPD) data were collected on a Bruker D8 diffractometer (PSD: Lynxeye, $\mathrm{Cu}-\mathrm{K}_{\alpha 1}, \mathrm{Ge}$ monochromator) in planar transmission mode. Neutron powder diffraction (NPD) data were collected on diffractometer D2B, ILL, Grenoble at temperatures of 300, 20, 16 and $4 \mathrm{~K}$. The wavelength was calibrated using XRPD refinement data on the same sample to give $\lambda=1.5923 \AA$. The ILL data used for the refinements were extracted from only the centre of the detectors to provide greater peak resolution.

A ${ }^{57} \mathrm{Fe}$ Mössbauer spectrum was recorded at $298 \mathrm{~K}$ with a constant acceleration spectrometer in transmission geometry using a $c a .400 \mathrm{MBq}{ }^{57} \mathrm{Co} / \mathrm{Rh}$ source. To avoid the effects of excessive absorption by the presence of $\mathrm{Pb}$ and $\mathrm{Bi}$, a sample enriched to $10 \%{ }^{57} \mathrm{Fe}$ was synthesised. The drive velocity was calibrated with the ${ }^{57} \mathrm{Co} / \mathrm{Rh}$ source and a natural iron foil. The chemical isomer shift data are reported relative to that of metallic iron at $298 \mathrm{~K}$.
The Rietveld method ${ }^{16}$ was used to refine the nuclear and magnetic structures of $\mathrm{FePbBiO}_{4}$ with the aid of the general structures analysis system (GSAS) ${ }^{17}$ and EXPGUI interface. ${ }^{18}$ Background intensity was modelled using a shifted Chebyschev polynomial with 25 terms, while peak shapes were modelled using a pseudo-Voigt function. Isotropic displacement parameters were assigned to $\mathrm{Fe}^{3+}$ and the equatorial $\mathrm{O} 2$, but anisotropic parameters were used for $\mathrm{Pb}^{2+} / \mathrm{Bi}^{3+}$ and the apical $\mathrm{O} 1$. The magnetic structure was modelled using a second unit cell $(P 1)$ containing only magnetic cations, with appropriate constraints applied to the magnetic moments to conform to a given model. The unit cell dimensions of the magnetic phase were constrained to those of the nuclear unit cell.

Magnetic susceptibility data were acquired using a Quantum Design MPMS SQUID under field cooled (FC) and zero field cooled (ZFC) conditions with an applied field of 100 Oe. No corrections for diamagnetism were applied since they are too small to provide a significant effect. A cooling and heating rate of $10 \mathrm{~K} \mathrm{~min}^{-1}$ was used, with measurements taken in 'Sweep' mode. The polycrystalline sample $(\sim 70 \mathrm{mg})$ was contained in a gelatin capsule, within a plastic straw.

\section{Results and discussion}

\subsection{Crystal structure}

The synthesised $\mathrm{FePbBiO}_{4}$ was dark brown and stable in air up to the melting point at $\sim 700{ }^{\circ} \mathrm{C}$. The ambient temperature Mössbauer spectrum, Fig. 3, shows a single $\mathrm{Fe}^{3+}$ doublet with a chemical isomer shift, $\delta$, of $0.39 \mathrm{~mm} \mathrm{~s}^{-1}$ and quadrupole splitting, $\Delta$, of $0.59 \mathrm{~mm} \mathrm{~s}^{-1}$. These values are typical of octahedral $\mathrm{Fe}^{3+}$ and confirm that the synthesis yields a product for which $100 \%$ of the $\mathrm{Fe}$ is present as $\mathrm{Fe}^{3+}$. XRPD data revealed the product to be single phase with a tetragonal, $P 4_{2} / m b c$, structure which is indicative of the schafarzikite structure. The unit cell parameters determined from Rietveld refinement against X-ray data were subsequently used to calibrate the NPD data, against which the structure was refined. The refined structural parameters are given in Table 1 for data obtained at ambient temperature and $4 \mathrm{~K}$. The relevant diffraction profiles corresponding to the refinement based on ambient temperature

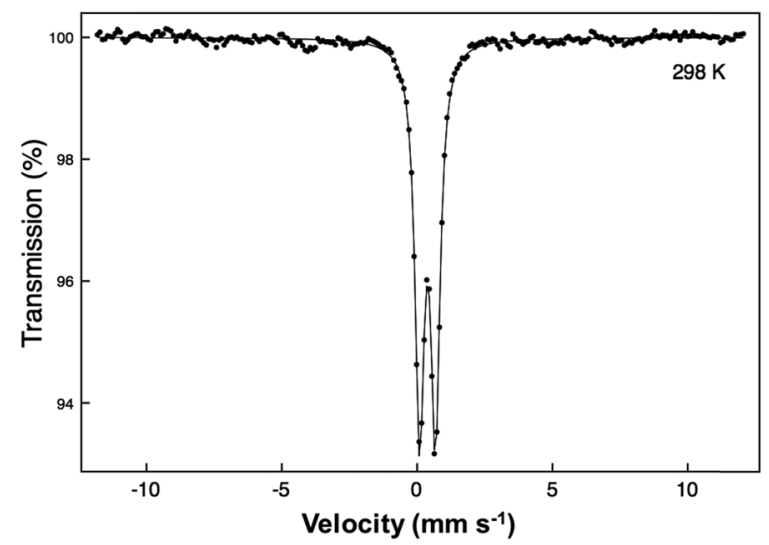

Fig. 3 The ambient temperature ${ }^{57} \mathrm{Fe}$ Mössbauer spectrum of $\mathrm{FePbBiO}_{4}$. 
Table 1 Refined structural parameters from NPD data from $\mathrm{FePbBiO}_{4}$ at $300 \mathrm{~K}$ and $4 \mathrm{~K}$ (the latter are given in italics)

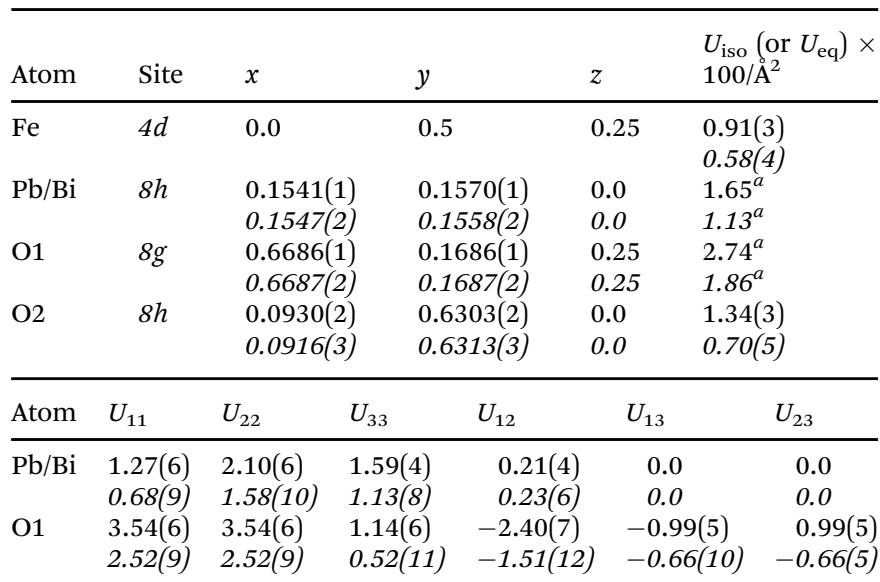

$P 4_{2} / m b c: a=8.48925(9)(8.4725(2)) \AA, c=6.10597(8)(6.1004(2)) \AA$, volume $=440.04(1)(437.90(3)) \AA^{3} . R_{\mathrm{wp}}=0.036(0.056) ; \chi^{2}=4.19(8.98)$. ${ }^{a}$ Anisotropic displacement parameters $\left(\right.$ all $\left.\times 100 / \AA^{2}\right)$ are given.

data are shown in Fig. 4 . The $\mathrm{Bi}$ and $\mathrm{Pb}$ ions were found to be randomly distributed on the channel wall site; it was found that this position and the apical $\mathrm{O} 1$ site had higher than expected isotropic displacement parameters (IDPs). Allowing anisotropy resulted in strongly anisotropic parameters (ADPs) as shown in Table 1 . These values are attributed to the presence of both $\mathrm{Pb}^{2+}$ and $\mathrm{Bi}^{3+}$ : the charge and size differences, as discussed in the Introduction, result in local displacements of the cations and the $\mathrm{O} 1$ ions, to which they are bonded. The effects of the ADPs are highlighted in Fig. 5, which focuses on this region of the structure. The local displacements of $\mathrm{Pb} / \mathrm{Bi}$ towards or away from the bonded $\mathrm{O} 1$ are indicated, and $\mathrm{O} 1$ moves in a perpendicular direction so that the $\mathrm{Fe}-\mathrm{O} 1$ bond distance will not change significantly. The displacements allow optimisation of the bonding requirements according to whether $\mathrm{Pb}^{2+}$ or $\mathrm{Bi}^{3+}$ is bonded to a particular $\mathrm{O} 1$ site. Table 2 gives important bond distances and angles and also provides bond valence sums (BVS ${ }^{19}$ for the cations and the full structure is shown in Fig. 1.

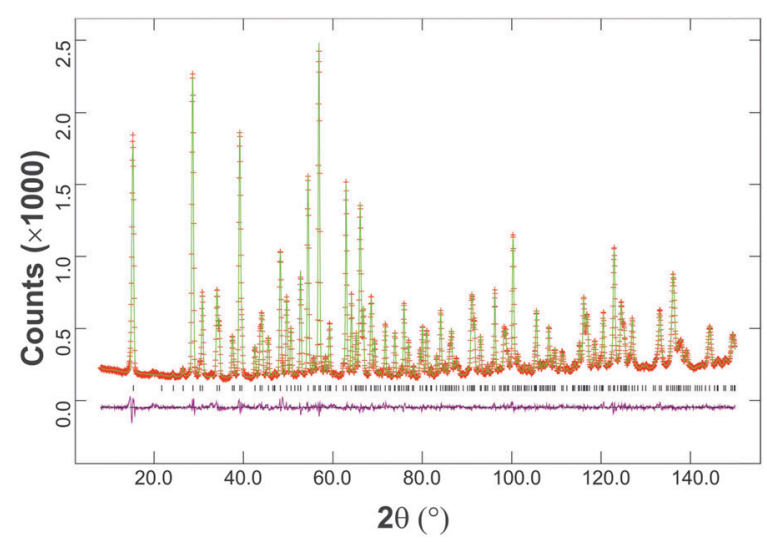

Fig. 4 Fitted neutron powder diffraction profiles at $300 \mathrm{~K}$ showing observed data (red crosses), calculated (green line) and difference (purple line). Reflection markers are shown below the diffraction profiles.

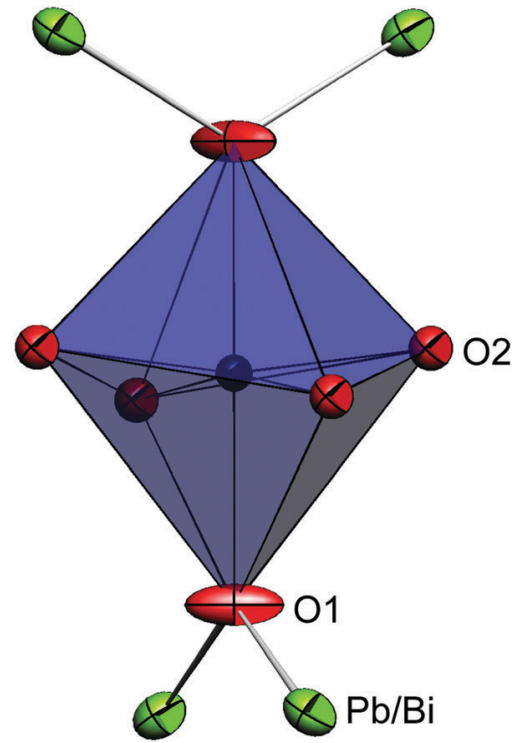

Fig. 5 Ion displacements represented by contours enclosing $70 \%$ of the neutron scattering.

Table 2 Significant bond distances, bond valence sums (BVS) and angles at $300 \mathrm{~K}$

\begin{tabular}{|c|c|c|c|c|c|}
\hline \multicolumn{2}{|l|}{ Bond } & \multirow{2}{*}{$\begin{array}{l}\text { Distance } / \AA ̊ \\
2.024(1)[\times 2] \\
2.0435(9)[\times 4]\end{array}$} & \multicolumn{3}{|l|}{ BVS } \\
\hline $\mathrm{Fe}$ & $\begin{array}{l}-\mathrm{O} 1 \\
-\mathrm{O} 2\end{array}$ & & & 2.83 & \\
\hline $\mathrm{Pb} / \mathrm{Bi}$ & $\begin{array}{l}-\mathrm{O} 1 \\
-\mathrm{O} 2\end{array}$ & $\begin{array}{l}2.1298(10) \ldots[\times 2] \\
2.159(2)\end{array}$ & $\mathrm{Pb}^{2+} 2.79$ & & $\mathrm{Bi}^{3+} 2.65$ \\
\hline
\end{tabular}

\begin{tabular}{ll}
\hline Bond & Angle ${ }^{\circ}$ \\
\hline O1-Fe-O1 & $180.0(0)$ \\
O1-Fe-O2 & $83.71(4)[\times 4]$ \\
& $96.29(4)[\times 4]$ \\
O2-Fe-O2 & $83.34(5)[\times 2]$ \\
& $98.05(5)[\times 2]$ \\
O1-Pb/Bi-O1 & $91.57(5)$ \\
& $90.89(5)[\times 2]$ \\
\hline
\end{tabular}

The unit cell volume (440.0 $\AA^{3}$, Table 1$)$ is similar to that of $\mathrm{FeSb}_{2} \mathrm{O}_{4}\left(439.5 \AA^{3}\right),{ }^{13}$ which reflects a balance in the effects of replacing $\mathrm{Fe}^{2+}$ with the smaller $\mathrm{Fe}^{3+}$ whilst, at the same time, substituting the larger $\mathrm{Pb}^{2+} / \mathrm{Bi}^{3+}$ combination for $\mathrm{Sb}^{3+}$. However, a contraction occurs along $a$ and an expansion along $c$ (for $\left.\mathrm{FeSb}_{2} \mathrm{O}_{4}: a=8.6157(1) \AA, c=5.9207(1) \AA\right)^{13}$. ${ }^{13}$ This effect is universally seen when oxidation occurs at the octahedral intrachain cation owing to enhanced electrostatic repulsions across the common edges of the linked octahedra.

Although the BVS for $\mathrm{Fe}^{3+}$ is close to that expected (Table 2), the determined $\mathrm{Pb} / \mathrm{Bi}$ site provides a highly "overbonded" location for $\mathrm{Pb}^{2+}$ whereas $\mathrm{Bi}^{3+}$ would be somewhat "underbonded". However, these values are to be expected since they are determined from the average $\mathrm{Pb} / \mathrm{Bi}$ and $\mathrm{O}$ ionic positions and are consistent with the ADP values, which represent an attempt to model the 

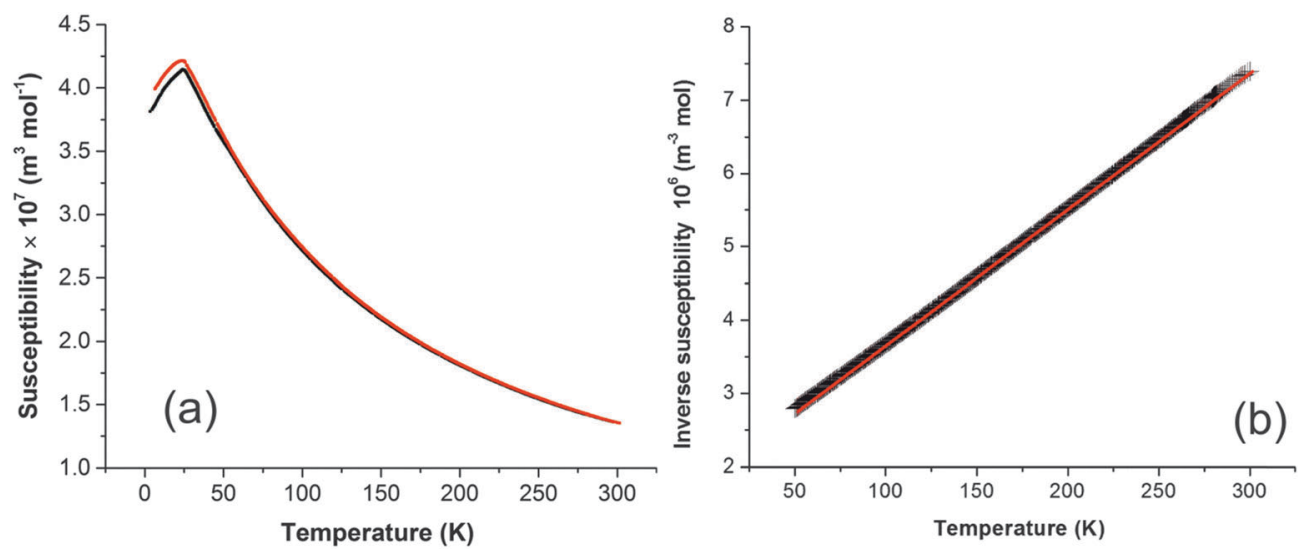

Fig. 6 (a) Plot of magnetic susceptibility against temperature for $\mathrm{FePbBiO}_{4}$ (FC data red, ZFC data black). (b) Plot of inverse susceptibility against temperature (data are black, linear fit is red).

distribution of the average scattering from the $\mathrm{O}, \mathrm{Pb}$ and $\mathrm{Bi}$ nuclei. Because of the electrostatic repulsion between $\mathrm{Fe}^{3+}$ cations within the chains of edge-linked octahedra along [001], the octahedra are extended in this direction; this provides $\mathrm{O} 2-\mathrm{Fe}-\mathrm{O} 2$ equatorial angles of $83.34(5)^{\circ}$ (where the angle bisector is parallel to [001]) and $98.05(5)^{\circ}$ (where the bisector is perpendicular to [001]).

\subsection{Magnetic properties}

Magnetic susceptibility $(\chi)$ data for $\mathrm{FePbBiO}_{4}$ are shown in Fig. $6 \mathrm{a}$ and suggest a simple paramagnetic-antiferromagnetic transition with a Néel temperature of $24 \mathrm{~K}$; a small divergence between the FC and ZFC susceptibilities below $T_{\mathrm{N}}$ is possibly due to a slight canting of the moments. Fig. $6 \mathrm{~b}$ shows the variation of $1 / \chi$ with temperature, which is exactly linear such that it is difficult to differentiate the data points and the least squares fit; the material therefore strictly obeys the CurieWeiss law: the slope corresponds to an effective moment of $\mu_{\text {eff }}=5.870(1) \mu_{\mathrm{B}}$ and the intercept on the temperature axis gives the Weiss constant, $\theta=-97(1) \mathrm{K}$. As expected for a $\mathrm{d}^{5}$ high spin cation, for which there is zero orbital contribution to the magnetic moment, the moment is in excellent agreement with the spin-only moment of $5.92 \mu_{\mathrm{B}}$. As is usual for materials with this structure, $-\theta$ is significantly greater than $T_{\mathrm{N}}$; this may be rationalised since $\theta$ will reflect the average exchange energy (intrachain and interchain) at temperatures above $T_{\mathrm{N}}$, whereas $T_{\mathrm{N}}$ is determined largely by the weaker interchain exchange interactions. $^{12}$

The low temperature magnetic order was explored by collecting NPD data sets at $4 \mathrm{~K}, 16 \mathrm{~K}$ and $20 \mathrm{~K}$. The nuclear structural parameters at $4 \mathrm{~K}$ are given in Table 1 and show no major changes compared with those at $300 \mathrm{~K}$. Symmetry allows a range of magnetically ordered structures. Fig. 2 shows the basic types of magnetic order that have been observed for $\mathrm{MSb}_{2} \mathrm{O}_{4}$ materials, but the actual order in these materials can be complex, with contributions from more than one of the types of order shown in Fig. 2. ${ }^{12}$ A separate magnetic phase with $P 1$ symmetry was therefore used in the low temperature refinements to allow complete flexibility. The principal order observed was found to be A-type with moments aligned along [100], $\mathrm{A}_{x}$, or the equivalent $\mathrm{A}_{y}$. Although a small $\mathrm{C}_{z}$ component was observed for the largest overall moment (at the lowest temperature, $4 \mathrm{~K}$ ), at higher temperatures no significant evidence for this was apparent. The refined moments are given in Table 3, where $\mu_{x}$ gives the A-type moment and $\mu_{z}$ the C-type component. The mixture of $\mathrm{A}_{x}$ and $\mathrm{C}_{z}$ components at $4 \mathrm{~K}$ corresponds to a small rotation of the moments by $6.3(8)^{\circ}$ away from the $x$-axis towards the $z$-axis. The NPD profiles at $300 \mathrm{~K}$ and $4 \mathrm{~K}$ are compared in Fig. 7 for $2 \theta<40^{\circ}$, where strong magnetic scattering is observed.

The NPD data show that $\mathrm{FePbBiO}_{4}$ and $\mathrm{FeSb}_{2} \mathrm{O}_{4}$ display the same principal magnetic order: $\mathrm{A}_{x}$-type with antiferromagnetic order within the chains of $\mathrm{FeO}_{6}$ octahedra. However, the overall exchange interactions appear to be weaker for $\mathrm{FePbBiO}_{4}$, since $T_{\mathrm{N}}(24 \mathrm{~K})$ is significantly lower than that for $\mathrm{FeSb}_{2} \mathrm{O}_{4}, 46 \mathrm{~K} .{ }^{2,3}$ The $\mathrm{Fe}^{3+} \cdots \mathrm{Fe}^{3+}$ direct exchange is probably weaker in $\mathrm{FePbBiO}_{4}$ because of the more contracted d-orbitals of $\mathrm{Fe}^{3+}$. It is also likely that the extended interchain covalent exchange pathway $(\mathrm{Fe}-\mathrm{O}-\mathrm{Pb} / \mathrm{Bi}-\mathrm{O}-\mathrm{Fe})$ is reduced in energy. Given the increased size of $\mathrm{Co}^{2+}$ compared with $\mathrm{Fe}^{3+}$, it is a little surprising that $\mathrm{CoSb}_{2} \mathrm{O}_{4}$ displays C-type order ${ }^{11}$ (with ferromagnetic order within a given chain of octahedra) whereas $\mathrm{FePbBiO}_{4}$ is A-type, which is normally associated with strong direct exchange. This feature can be rationalised by the difference in electron configurations within the $t_{2 g}$ orbitals participating in the direct exchange: $\left(t_{2 g}\right)^{5}$ and $\left(t_{2 g}\right),{ }^{3}$ respectively. In contrast to $\mathrm{Fe}^{3+}$, where all $\mathrm{t}_{2 \mathrm{~g}}-\mathrm{t}_{2 \mathrm{~g}}$ overlaps will result in antiferromagnetic exchange, for $\mathrm{Co}^{2+}$ both antiferromagnetic and ferromagnetic exchange interactions are present depending on the electron occupancy of the overlapping orbitals; this will reduce the overall tendency for antiferromagnetic chain order.

The refined magnetic moment at $4 \mathrm{~K}, 3.74(6) \mu_{\mathrm{B}}$, is lower than the ideal value of $5 \mu_{\mathrm{B}}$ for $\mathrm{Fe}^{3+}$. However, the value is

Table 3 Magnetic data for $\mathrm{FePbBiO}_{4}$ from NPD refinements

\begin{tabular}{llll}
\hline Temperature $/ \mathrm{K}$ & $\mu_{x} / \mu_{\mathrm{B}}$ & $\mu_{z} / \mu_{\mathrm{B}}$ & $\mu_{\text {total }} / \mu_{\mathrm{B}}$ \\
\hline 4 & $3.72(5)$ & $0.41(7)$ & $3.74(6)$ \\
16 & $3.17(6)$ & 0 & $3.17(6)$ \\
20 & $2.70(7)$ & 0 & $2.70(7)$
\end{tabular}




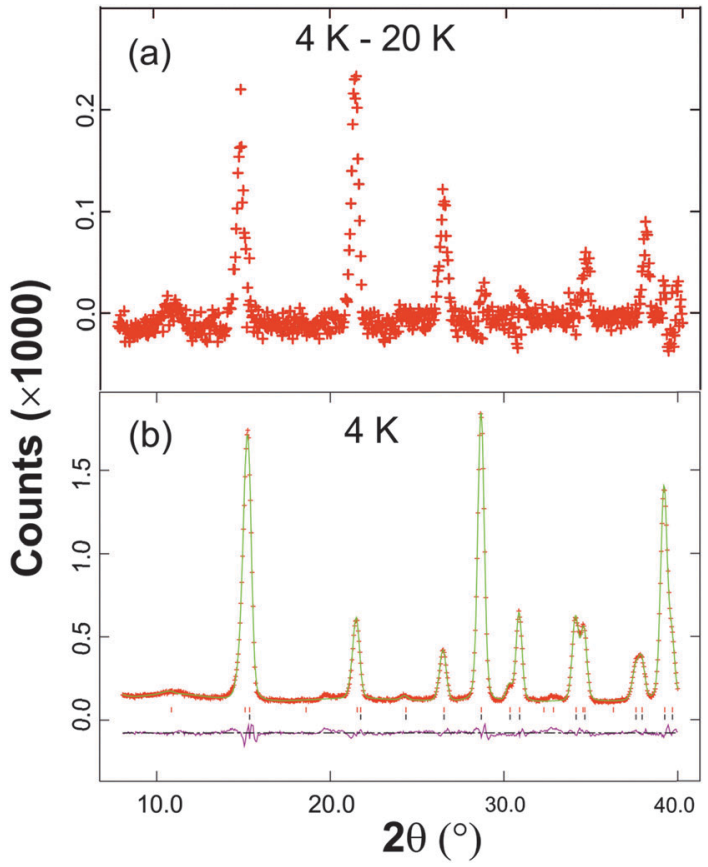

Fig. 7 (a) The difference between the observed NPD profiles at $4 \mathrm{~K}$ and $20 \mathrm{~K}$ demonstrating the areas of large magnetic scattering. (b) Fitted neutron powder diffraction profiles at $4 \mathrm{~K}$ for $2 \theta<40 \mathrm{~K}$ : observed data (red crosses), calculated (green line) and difference (purple line). Reflection markers for the magnetic and nuclear unit cells are shown in red and black, respectively.

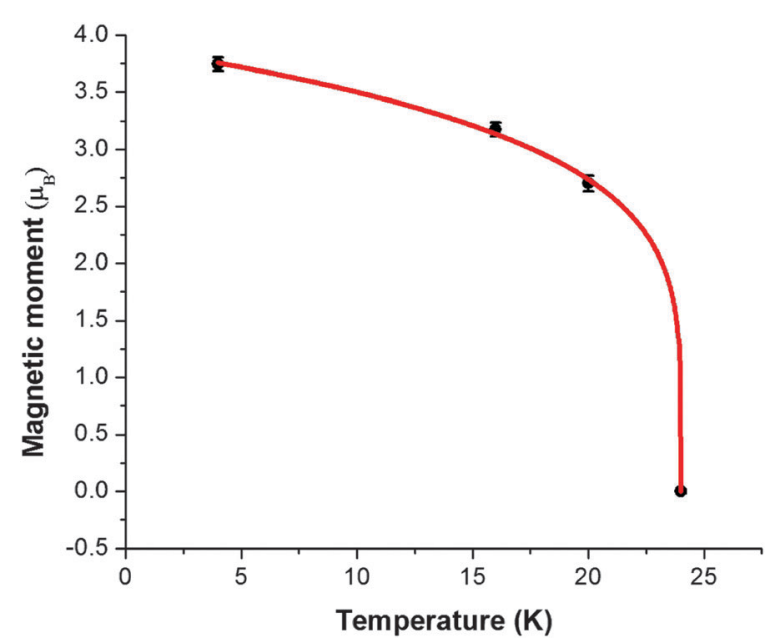

Fig. 8 Variation of ordered magnetic moment $(\bullet)$ with temperature fitted to a Brillouin function (red line).

similar to values normally seen for $\mathrm{Fe}^{3+}$ compounds, and the reduced moment is caused by zero-point quantum mechanical effects and ligand-to-metal electron transfer inherent to covalence within the $\mathrm{Fe}-\mathrm{O}$ bonds.

The overall magnetic moments are plotted against temperature in Fig. 8. The Néel temperature from the susceptibility measurements has been included and the resulting four data points fit well to the Brillouin function $\mu=\mu_{0}\left(1-\frac{T}{T_{\mathrm{N}}}\right)^{\beta}$ where the Néel temperature, $T_{\mathrm{N}}$, is fixed at $24 \mathrm{~K}, \mu_{0}$ is the zeropoint moment and $\beta$ is an exponent that is linked to the nature of the transition. In this case, fitting the data results in the parameters: $\mu_{0},=3.89(4) \mu_{\beta}$, and $\beta=0.20(1)$. Although lower than that normally found for magnetic order in isotropic materials (for which $\beta$ is usually $c a$. 0.3), $\beta$ is typical for low dimensional systems and is similar to the value of 0.18 reported for $\mathrm{FeSb}_{2} \mathrm{O}_{4}{ }^{3}$

\section{Conclusions}

Tetragonal $\mathrm{FePbBiO}_{4}$ has been synthesised and its unit cell shows a contraction along $a$ and an expansion along $c$ compared with that of $\mathrm{FeSb}_{2} \mathrm{O}_{4}$. These changes are the result of enhanced electrostatic repulsion between the $\mathrm{Fe}^{3+}$ cations within the chains of octahedra oriented along [001]. The $\mathrm{Bi}^{3+}$ and $\mathrm{Pb}^{2+}$ ions are randomly distributed on the sites which form the walls of the channels within the structure, and their bonding preferences result in small differences to their ionic positions; these are reflected in the atomic ADP values. Below the Néel temperature $(24 \mathrm{~K}), \mathrm{FePbBiO}_{4}$ displays A-type antiferromagnetic order with moments perpendicular to [001]. The magnetic moment of $\mathrm{Fe}^{3+}$ at $4 \mathrm{~K}$ is $3.74(6) \mu_{\mathrm{B}}$, slightly lower than expected for this cation in well-ordered magnetic oxides.

\section{Acknowledgements}

We thank EPSRC for financial support of this research (EP/L014114/1) and EPSRC, EU and ILL for the provision of NPD facilities. We are grateful to Dr Emma Suard for assistance in collecting the NPD data and Dr Martin Lees for the use of a SQUID at the Department of Physics, University of Warwick. The X-ray diffractometers used in this research were obtained through Birmingham Science City: Creating and Characterising Next Generation Advanced Materials (West Midlands Centre for Advanced Materials Project 1), with support from Advantage West Midlands (AWM) and part funded by the European Regional Development Fund (ERDF). Data associated with the results shown in this paper are accessible from the University of Birmingham Archive: http://epapers.bham.ac.uk/2162/.

\section{References}

1 J. A. Gonzalo, D. E. Cox and G. Shirane, Phys. Rev., 1966, 147, 415. 2 F. Varret, P. Imbert, A. Gerard and F. Hartmann-Boutron, Solid State Commun., 1968, 6, 889.

3 R. Chater, J. R. Gavarri and A. W. Hewat, J. Solid State Chem., 1985, 60, 78.

4 G. Tammann, Z. Anorg. Allg. Chem., 1925, 149, 21.

5 E. Koyama, I. Nakai and K. Nagashima, Nippon Kagaku Kaishi, 1979, 6, 793.

6 J. R. Gavarri, G. Calvarin and B. Chardon, J. Solid State Chem., 1983, 47, 132.

7 H. T. Witteveen, Solid State Commun., 1971, 9, 1971.

8 S. Ståhl, Ark. Kern. Min. Geol., 1943, 17B, 1. 
9 M. T. Atanasova, A. M. Strydom, C. J. H. Schutte, L. C. Prinsloo and W. W. Focke, J. Mater. Sci., 2014, 49, 3497.

10 J. R. Gavarri and A. W. Hewat, J. Solid State Chem., 1983, 49, 14.

11 B. P. de Laune and C. Greaves, J. Solid State Chem., 2012, 187, 225.

12 J. Cumby, B. P. de Laune and C. Greaves, J. Mater. Chem. C, 2016, 4, 201.

13 M. J. Whitaker, R. D. Bayliss, F. J. Berry and C. Greaves, J. Mater. Chem., 2011, 21, 14523.

14 A. M. Abakumov, M. G. Rozova, E. V. Antipov, J. Hadermann, G. Van Tendeloo, M. V. Lobanov, M. Greenblatt, M. Croft,
E. V. Tsiper, A. Llobet, K. A. Lokshin and Y. S. Zhao, Chem. Mater., 2005, 17, 1123.

15 R. D. Shannon, Acta Crystallogr., Sect. A: Cryst. Phys., Diffr., Theor. Gen. Crystallogr., 1976, 32, 751.

16 H. M. Rietveld, J. Appl. Crystallogr., 1969, 2, 65.

17 A. C. Larson and R. B. Von Dreele, General Structural Analysis System (GSAS), Los Alamos National Laboratory LAUR, 1994, pp. 86-748.

18 B. H. Toby, J. Appl. Crystallogr., 2001, 34, 210.

19 I. D. Brown and D. Altermatt, Acta Crystallogr., Sect. B: Struct. Sci., 1985, 41, 244. 